\title{
HOW DOES THE INSTITUTIONAL CONTEXT OF AN EMERGING ECONOMY SHAPE THE INNOVATION TRAJECTORY OF DIFFERENT TYPES OF COMPANIES? A CASE STUDY OF INDIA
}

\author{
Harini Mittal ${ }^{1, \mathrm{a}, *}$ \\ ${ }^{1} \mathrm{NY}$ Business and Information Systems Department, Bronx Community College, City University of \\ New York, 2155, University Avenue, Bronx, NY, USA. \\ ârini.mital@bcc.cuny.edu \\ ${ }^{*}$ Corresponding author
}

Cite as: Mittal, H. (2020). How does the institutional context of an emerging economy shape the innovation trajectory of different types of firms? A case study of India, Ekonomicko-manazerske spektrum, 14(2), 36-51.

Available at: dx.doi.org/10.26552/ems.2020.2.36-51.

Received: 6 April 2020; Received in revised form: 30 April 2020; Accepted: 5 May 2020; Available online: 17 September 2020

\begin{abstract}
Institutional voids faced by emerging economies have received a lot of attention in recent literature. However, the impact of institutional voids in an emerging economy on the level of company innovation strategies and output is a less researched topic. Using India as a case study, this paper presents a qualitative assessment of the impact of the institutional context of this emerging economy on innovation strategies and consequent outputs of private Indian companies of various sizes and ages. Primary data for the study were collected by means of surveys, in-depth interviews, and secondary data sources including government reports, World Bank and United Nations reports, research articles, and in-depth industry surveys. The paper concludes that in India, large companies and start-ups are more innovative. Most innovations are imitative in nature, and/or driven by customer requirements, and/or international quality norms. "New-to-the-world" innovations are scarce and are mostly driven by multinational corporations (MNCs), government institutions, and to some extent large Indian companies. The paper concludes that in a rapidly emerging economy like India, large companies are more innovative because of their resilience, internal systems, and capabilities that can overcome voids, and exploit opportunities. The fast-paced transitions have created more opportunities for start-ups than small and medium-sized enterprises (SMEs), thereby creating unequal innovation opportunities for companies of different sizes and ages, as distinct coping strategies are required for innovation to occur.
\end{abstract}

Keywords: innovation trajectory, India, institutional theory, institutional context, institutional voids, innovation strategies, emerging economy, innovation outputs

JEL classification: L26, O30

\section{Introduction}

Numerous studies show that institutional context, characterized by a system of laws and formal and informal mechanisms that define how a country's industry, economy, and society should operate, impacts innovation in an economy (Stankevice and Jucevicius, 2013; Chowdhury et al., 2015; Simon-Moya et al., 2014; Mueller et al., 2013). Casper's (2009) study 
posited that companies focus on innovation strategies that are supported by the dominant national institutional context. According to Lewin and Volberda (2005), environments or contexts where technical and economic demands are dominant favor radical innovations, whereas contexts where social demands are dominant foster incremental ones. Whitley (2000) identified five types of innovation strategies across six different economic organizations or business systems that evolved from variations in institutional context in a market economy.

Emerging economies present a wide range of variations in their institutional contexts. For example, emerging economies such as India have institutional voids that inhibit innovation, like weak policy and governance frameworks; lack of technical support, interactions with formal science and technology organizations; absence of social and economic safety nets; and absence of formal credit mechanisms (Voeten et al., 2017; Khanna and Palepu, 2000). To overcome these voids, companies devise strategies for survival that are specific to their environment. These strategies also differ according to company characteristics, such as size and age. Research on the relationship between such institutional voids and innovation inputs, outputs, and varying company-level coping strategies based on company characteristics has been limited, especially in the field of emerging economies. This qualitative research paper seeks to address this gap with a case study of India, an important, rapidly emerging economy with varied degrees of complexities, voids, and unique opportunities in its institutional context. In 2013, India ranked sixty-sixth out of 142 countries in the Global Innovation Index (GII), as published by the World Intellectual Property Organization (WIPO) and INSEAD. In 2019, India ranked fifty-second out of 129 countries. A further look at the input sub-indices of the ranking and score shows an improvement in human capital and research, infrastructure, market sophistication, and business sophistication, while the input sub-index ranking and score for institutions remained unchanged. The knowledge and technology output sub-index ranking and score also remained the same, while creative outputs saw a decline from 2013 to 2019. Such transitions provide an interesting assortment of challenges and prospects for innovation by private companies, which in turn poses certain questions. Are the institutional voids and opportunities different for larger companies as compared to smaller companies; younger companies as compared to older companies? Which of these are more innovative? What are the innovation vehicles for each of these categories? What innovation strategies do each of these companies adopt? What are the innovation outputs and how do they differ?

The study at hand uses both primary and secondary data from India to identify institutional voids and opportunities and to recognize different innovation strategies used by private companies based on their size and age. From these observations, the study derives a qualitative assessment of the innovation trajectory of Indian private industry. This is unique since the study maps voids and opportunities in each pillar of the institutional context to innovation strategies and outputs of Indian companies of all different sizes and ages. The study is distinctive in its comprehensive nature and coverage.

The paper is organized as follows: Section two presents literature review of the three pillars of institutional context, their links to company-level innovation outputs, and strategies to arrive at the research gap. Section three offers a hypothesis. Section four outlines the model and methodology for the study. Section five presents the results. Section six discusses the results and presents an assessment of the innovation trajectory of India's private sector. Section seven offers suggestions for future research.

\section{Literature review}

\subsection{Institutional context - the three pillars}

Voeten et al. (2017) summed up several definitions of institutions as "rules of the game in a society" (North, 1990), the existence of "formal laws defining a playing field, facilitating the 
activities of certain players while constraining the efforts of others" (Hwang and Powell, 2005), and "prevalent methods of doing things in contexts" (Nelson, 1988).

Other authors categorize institutions as formal and informal. Scott (1995) identified three pillars of institutional context: regulatory, normative, and cognitive. Laws, regulations and government policies, and the resulting investment in innovation inputs represent the regulatory pillar. Culture provides cues that shape the behavior and education in a society; it constitutes the normative pillar. The cognitive pillar comprises education, knowledge, and skills in a country (Simon-Moya et al., 2014). In this study, we use Scott's framework to analyze the institutional context of India.

\subsection{Institutional voids, opportunities, company-level innovation strategies, and outputs}

Studies that evaluate the impact of institutions on company-level innovation output or performance conceptualize institutional context as a single variable constructed from multiple factors (Estrin et al., 2018; North, 1990; Wu et al., 2017; Yan et al., 2018); or look at the impact of one single aspect of institutional context such as public R\&D subsidies (Iris et al., 2013) or government support on firm level innovation performance; or use a multi-dimensional construct to explore the distinct dimensions in institutional environments (Berry et al., 2010; Estrin et al., 2018; Yan et al., 2018). For example, the maturity of market environment in a host country has been differentiated from its Intellectual Property Rights (IPR) protection (Castellacci, 2015). Almost all these studies concentrate solely on the regulatory pillar either as a single construct or a multi-dimensional construct.

In these studies, company-level innovation output or performance is measured using several variables such as IPRs (Barros, 2015), product novelty, process novelty (Jie et al., 2019) type of innovation - incremental or radical, number of innovations over the previous year (Cuili et al. 2013), etc.

As far as company-level innovation strategies are concerned, measures such as R\&D intensity (ratio of $R \& D$ expenditure to sales); $R \& D$ personnel; presence of a dedicated $R \& D$ department; new management practices; organization culture; collaboration with other companies, academia, and/or scientific institutions are commonly used.

Research focused on emerging economies that use multiple constructs to represent impact of institutional context on company-level innovation output or performance and company-level innovation strategy, either concentrate on a particular category of companies, such as multinational enterprises from emerging markets (Jie et al., 2019), or group-affiliated firms (GAFs) vs standalone firms (SAFs) (Castellacci, 2015), etc.; or study a single construct of institutional context, such as IPR (Barros, 2015).

Studies that assess impact of institutions of emerging economies on innovation outputs of the economy as a whole focus mainly on the regulatory pillar and to some extent the cognitive pillar of institutions for assessing institutional voids and opportunities. They use output measures that are indicative of the innovation capability of an economy, such as research and development (R\&D) expenditure, FDI flows, quantity and quality of research publications, and the number and quality of patents issued (Fan, 2018, Cornell University; INSEAD; WIPO, 2019). Such studies also fail to capture the impact of these country-level innovation outputs on innovation performance at company level.

In addition to the above, it has been observed that in rapidly transitioning emerging economies, the normative pillar plays a vital role in areas where the regulative and cognitive pillar have voids (Voeten et al., 2017). Additionally, in such economies, different types of companies adapt differently. For example, Castellacci's (2015) comparative study of companies in Latin American countries revealed that GAFs are more resilient to rapid transitions as compared to SAFs, and hence are more innovative. An analysis of the impact of 
institutional context on the innovation trajectory of private industry is therefore incomplete without a comprehensive exploration of the effect of the opportunities and voids resulting from each of the pillars of the institutional context on the innovation strategies and outputs of companies, differentiated by characteristics like size and age. (Zuleta, 2007)

\section{Hypotheses}

\subsection{Voids and opportunities in the regulatory pillar in india and their implications for innovation in large and small indian companies}

Intellectual property laws, tax incentives, governance mechanisms, and programs/initiatives including investment in public R\&D determine the quality of a country's regulatory pillar of its institutional environment for innovation. India's new IP laws, although thorough, face bottlenecks in enforcement. Awareness of IP legislation and practices is also limited. Tax incentives for R\&D are effective only partially and in a handful of sectors, due to lack of accountability for outcomes and high transaction costs in deriving benefits (Shah et al., 2014). There are gaps in governance, such as weak and delayed enforcement of laws, excessive regulation, political instability, and security concerns (Fulvio, 2015; Voeten et al., 2017; CSIRNISTADS, 2014). On the positive side, Indian government introduced several programs and incentives to promote startups and Foreign Direct Investments (FDI) (IBEF, 2019).

In emerging markets, according to the institutional void thesis, large business groups make up for the lack of well-functioning institutions; they tend to perform better and be more innovative in countries with weaker and less efficient institutional setups (Chang et al., 2006). Further, when confronted with a process of institutional transition and market development, these large companies, being resilient organizations, will respond by becoming more efficient and more innovative over time, according to the organization resilience thesis (Chari and David, 2012).

India has the characteristics of oligopolistic capitalism where the benefits of economic growth are disproportionately appropriated by the wealthiest and have failed to trickle down to the poor (Shah et al., 2014). Approximately ten families control more than $80 \%$ of the stock in the country's largest corporations (Malhotra, 2009 in Kshetri and Nir, 2011). According to the Asian Development Bank, large Indian companies have won most of the lucrative government contracts, hold power over the country's natural resources and have "privileged access to land" (Shah et al., 2014). They also effectively build internal systems to fill the gaps in the institutional infrastructure (Khanna and Palepu, 2010). On the other hand, there are around 42.5 million registered \& unregistered small and medium-sized enterprises (SMEs) amounting to $95 \%$ of the total industrial units in the country, employing $40 \%$ of India's workforce; they contribute $45 \%$ of the manufacturing output, but only $6.11 \%$ of the manufacturing GDP. Hence, theoretical arguments as well as secondary data indicate that large companies are better positioned to take advantage of transitions in the regulatory pillar in the Indian institutional context. It can therefore be expected that:

Hla: Large Indian companies are more innovative than small and medium-sized enterprises (SMEs) and start-up firms, in response to the voids and opportunities in the regulatory pillar of the institutional context, due to having access to more resources.

Public R\&D spending, subsidies, and incentives form an important input of the regulatory pillar of any economy, with an impact on company-level innovation. Research indicates a positive effect of public $R \& D$ financing on private $R \& D$ expenditure (Dominique and Pottelsberghe, 2000; Jyrki, 2005). However, the impact of such financing on company size is ambiguous. In Finland, public R\&D funding increases private funding in larger companies 
more than does in smaller ones (Jyrki, 2005), while the opposite was true in Israel (Saul, 2002) and Spain (Xulia and Consuelo, 2008). Iris, Thomas and Fischer (2013) in their study of the Austrian transport sector found that small, young, and technologically specialized companies are more likely to realize behavioral additionalities such as private investment in newer, bigger, and collaborative projects. Research also indicates that public $R \& D$ financing stimulates private $R \& D$ spending in certain sectors more than others depending on the country (Xulia and Consuelo, 2008; Dominique and Pottelsberghe, 2000).

With respect to emerging economies, Ruifa et al. (2011) found that private R\&D investment in Chinese agricultural sector would grow more rapidly if the government shifted public resources from technology development to basic R\&D.

In India, while the ratio of R\&D expenditure to GDP has been declining from 2008-09 (NSTMIS, 2017), India's share of global R\&D increased substantially-from $1.8 \%$ in 1996 to $2.9 \%$ in 2017 (GII, 2019). R\&D continues to be driven mainly by the government sector in India, especially by the central government (Government of India Ministry of Finance Department of Economic Affairs Economic Division, 2018). Accordingly, based on the literature reviewed, the study posits that:

H1b: Public R\&D financing stimulates private $R \& D$ financing in India.

Hlc: The positive effect of public $R \& D$ financing on private $R \& D$ financing in India differs according to company size, age, and the industry sector in question.

Studies support the view that public R\&D support helps to create partnerships with new or diversified partners in the public and private sectors (Fier et al., 2006; Shipp et al., 2006). Such collaborations and joint R\&D activities continue even once the project has expired (Fier et al., 2006; Shipp et al., 2006). Iris et al. (2013) proved that additionality effects of collaboration are highest in SMEs and startups, specifically technology-oriented ones. They also demonstrated that companies with less experience in a specific research field benefitted more from such collaborations. Accordingly, the study hypothesizes:

H1d: Younger and smaller companies benefit most from collaborative R\&D between the public sector and private companies and/or amongst private companies only.

Foreign Direct Investment (FDI) inflows bring new products, technologies, and advanced management experience into the recipient countries. They create competition for domestic companies and force these companies to innovate to survive the competition. A knowledge spillover occurs, as does development of ancillary and service companies to cater to the foreign companies (Shah et al., 2014), which fosters innovation in the recipient countries. FDI inflows to India (Fig 1) rose consistently, thanks to the liberalized FDI policy and the Make in India (MII) campaign. In 2015, India surpassed China in capital investment. 


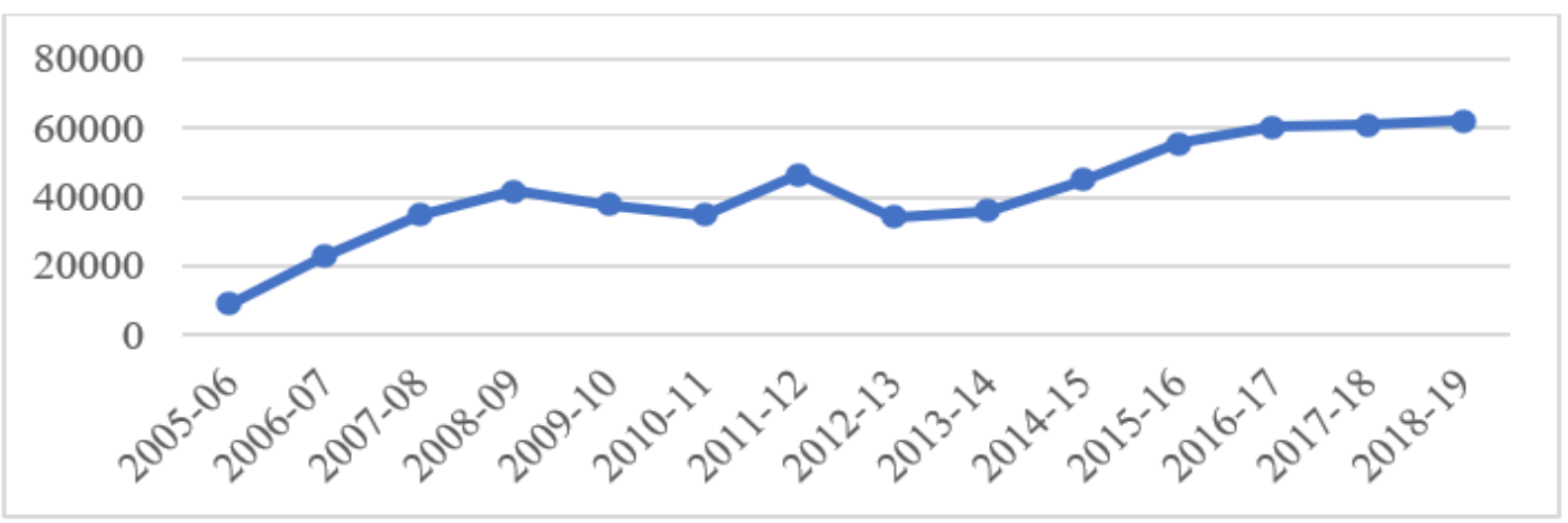

Source: Fact sheet on FDI, Department of Promotion of Industry and Internal Trade

Therefore, the author hypothesizes that:

H1e: FDI inflows foster innovation in private Indian companies.

\subsection{Voids and opportunities in the normative pillar in india and their implications for innovation in large and small indian companies}

Culture serves as the normative pillar as it provides cues that shape behavior and education in a society. A pro-innovative and entrepreneurial culture is characterized by high individualism combined with low power distance and weak ambiguity avoidance (Hofstede, 1991). The barriers to innovation in Indian culture range from high power distance exhibiting itself in a strong need for control, individualism demonstrated by poor teamwork, high uncertainty avoidance leading to weak strategic outlook, achievement culture driven by philosophical and intellectual pursuits rather than action-orientation and physical activity, and moderate levels of masculinity affecting the degree of experimentation (Afza, 2005; Sinha and Kanungo, 1997; Krishnan, 2010 in Shah, Gao and Mittal, 2014).

Since $95 \%$ of Indian organizations are family-owned, their ability to innovate and adapt to new technologies is also a major challenge by virtue of their ownership structures and management styles (Shah, Gao, \& Mittal, 2014). In recent years however, entrepreneurship is being perceived by the young generation as a worthwhile pursuit and India is witnessing increasing levels of entrepreneurship (Government of India; Ministry of Commerce and Industry - Department of Industrial Policy and Promotion, 2018). Hence, older companies that are typically family-owned could be less innovative than newer startups.

H2: Newer startups are more innovative than older companies in India because the traditional Indian cultural context did not support corporate innovation while the evolving cultural context does.

\subsection{Voids and opportunities in the cognitive pillar in india and their implications for innovation in large and small indian companies}

The cognitive pillar comprises knowledge and skills in a society represented by its demographic constitution. Innovation is impacted by demographic characteristics such as population size, age and gender, education, and the level of immigration. In small populations, complex technology will tend to be lost as a result of random loss or incomplete transmission (the Tasmanian effect). Large populations have more inventors and innovators and are more resistant to loss by chance. (Richerson et al., 2009). Research has found that people aged 50 
and over prefer to use their innovation skills significantly less than those between ages 20-29 and 40-49 (Lerouge et al., 2005). People with high levels of education have a higher likelihood of being innovative due to their advanced education and training. Immigration helps in crosspollination of ideas and promotes creative entrepreneurship.

India will have the advantage of large human capital, as its working age population increases over the next 20 years [Fig. 2]. However, this GDP projection may not be attainable if the skill sets of this young population do not improve (Periyanayagam and Goli, 2012).

Figure 2: Changes in India's working age population (15-64) in millions

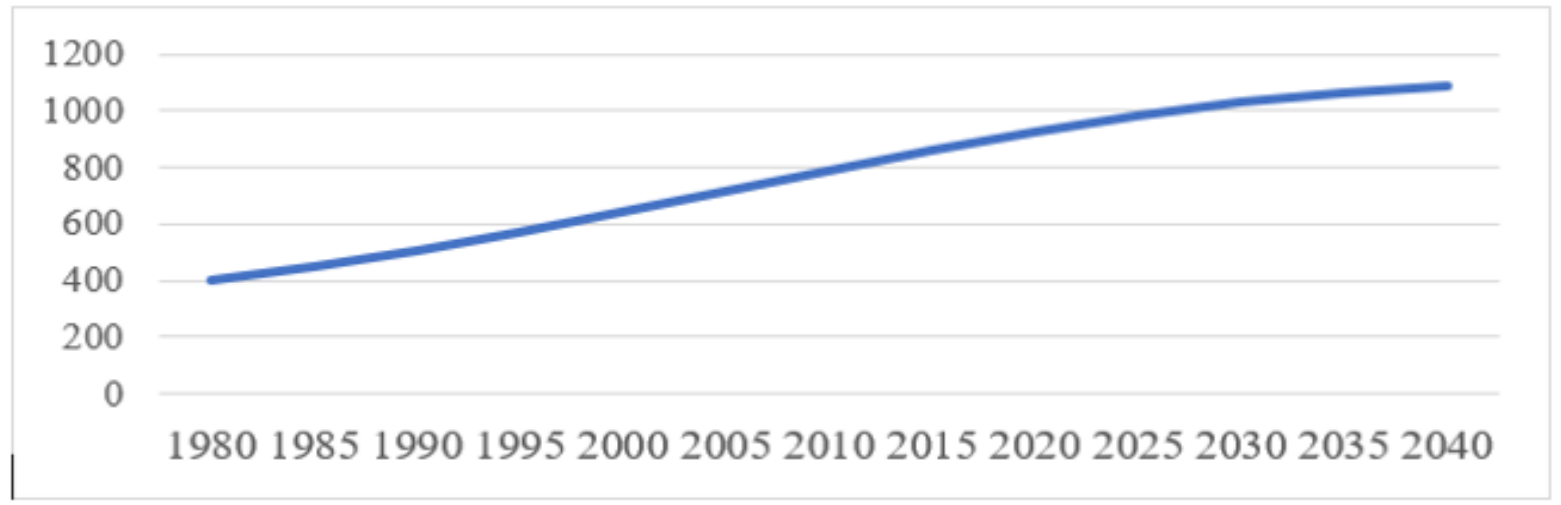

Source: (United Nations; Department of Economic and Social Affairs; Population Divisiton, 2019)

According to the 2011 census, $37 \%$ of Indians of the age of twenty-five years or older were illiterate, $89.7 \%$ of them had higher secondary or lower level of education, and only $9.1 \%$ had an undergraduate degree or higher qualification (Office of Registrar General of India and Census Commissioner, 2011). In addition to the low levels of education, the Indian primary and secondary education system places emphasis on rote memorization and grades. In the higher education system, there is a huge variation in quality, with very few good institutions at the higher end of the spectrum (Shah et al., 2014). This has led to many students traveling abroad for higher education which resulted in a long-term brain drain (Shah et al., 2014). The highly skilled expatriates who were once considered a part of this brain drain have now turned into an advantage for India as the cross-pollination of ideas and cultures has become an important source of intellectual, entrepreneurial, and capital investments in India (Shah, Gao, \& Mittal, 2014). The influx of knowledge networks and capital through Indian diaspora, although encouraging, does not suffice to fill the skill gap. The Indian demographic dividend can only be an advantage if the education system rises up to the challenge to provide the necessary skill sets.

H3: Lack of adequate skills is a void in the normative institutional context for innovation in India across large companies, SMEs and startups, despite country's massive demographic dividend.

\section{Model and Methodology}

The following table outlines the measures used across the categories of large companies, SMEs, and startups in India, to test the hypotheses identified in the previous section. These measures have been identified based on the literature review in section two. 
Table 1: Hypotheses and measures

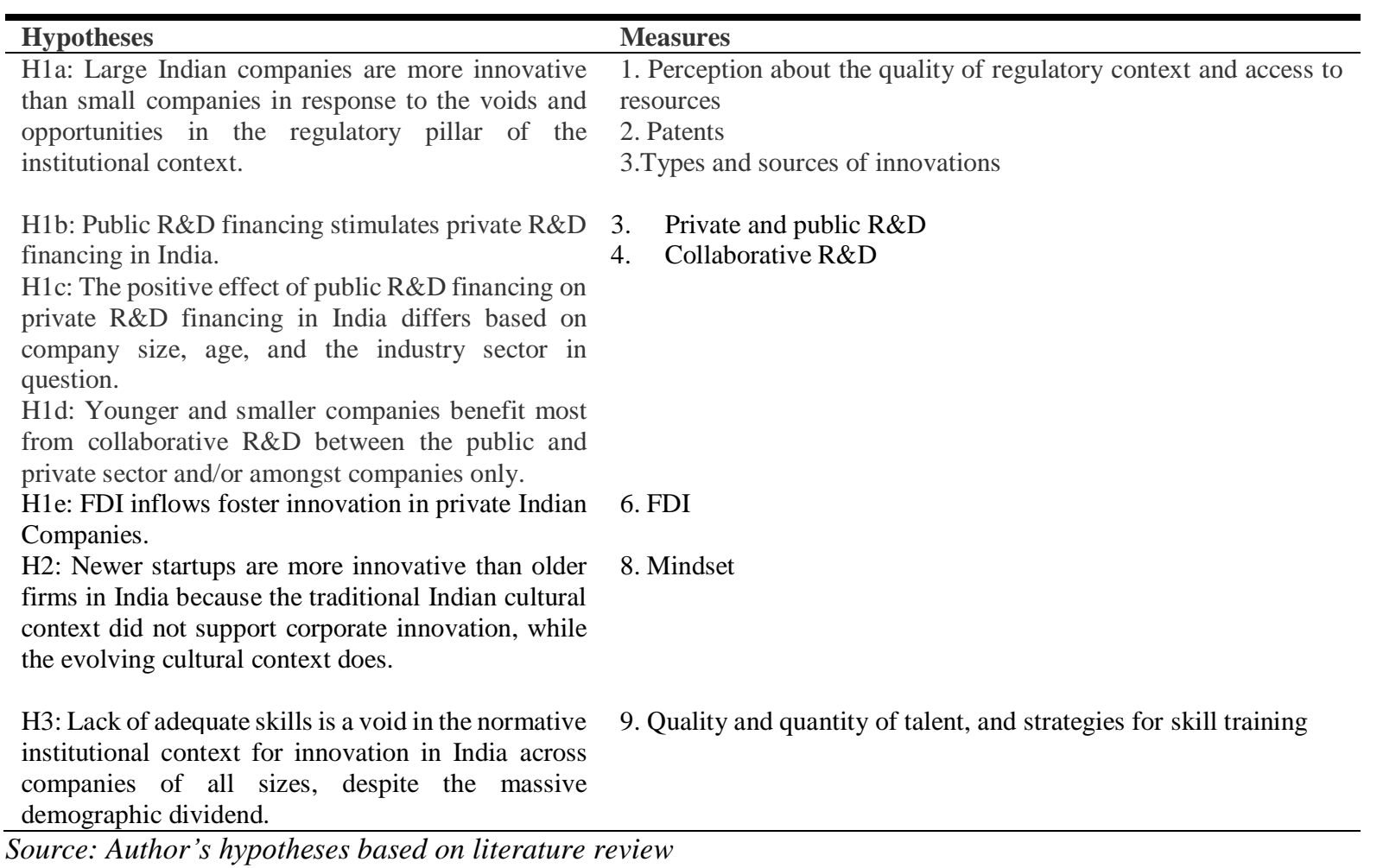

The author used a case study of the Indian private industry to aid in her research, as she could explore in detail the patterns and relationships that emerged out of it, instead of relying solely on general knowledge of a problem domain or making associations along generalized relationships between problem descriptors and conclusions. The study at hand uses multiple sources of information to conduct a detailed, descriptive, and qualitative inquiry and analysis.

The study involved primary data collection by means of surveys, in-depth interviews, and secondary data sources including government reports, World Bank and United Nations reports, research articles, and the following three major exhaustive surveys:

1. Indian National Innovation Survey of 9001 largely micro, small, and medium-sized enterprises (MSMEs) (CSIR-NISTADS, 2014);

2. GE Global Innovation Barometer-India report based on interviews of 150 Innovation Business Executives from large companies (Edelman Intelligence, 2018);

3. Research project involving in-depth case studies of five SMEs in India by the Tilburg University and the Radboud University in the Netherlands.

Primary data was collected by means of surveys on the SurveyMonkey website from forty innovation professionals (fourteen from large companies, thirteen from SMEs, thirteen from micro companies) from India. The questionnaire was validated and corrected for ambiguities by testing on a small sample before the actual survey was conducted. It had both multiple choice and open-ended questions. The author followed up the survey up with in-depth interviews with seven of the respondents (list provided in Appendix-1), carefully picked based on the survey results.

\section{Results}

\subsection{Perception of the quality of regulatory context and access to resources}

While large companies are optimistic about the government's policies (Edelman Intelligence, 2018), SMEs are finding it difficult to innovate (CSIR-NISTADS, 2014). 
Knowledge acquisition and transfer are far more challenging for SMEs than they are for larger companies (CSIR-NISTADS, 2014; Voeten et al., 2017). Access to finances for innovation for SMEs in general is a limiting factor in India (Shah et al., 2014). The primary survey and interview results corroborated these findings. For example, large established Indian pharmaceutical companies find it easier to produce in India than in the US, as the FDA regulations are more stringent than those of its counterpart in India. Oversight and enforcement are weaker, and thus more conducive for larger companies. The new China substitution policy encourages indigenous manufacturing. However, large companies and SMEs find the prerequisites cumbersome. According to the respondents, SMEs in general grapple with limited formal credit, no fall back mechanism for failure, and limited resources for innovation. They rely on a network of family and friends for funding and resources.

However, several government programs and incentives have resulted in a massive boom in startups (Government of India; Ministry of Commerce and Industry - Department of Industrial Policy and Promotion, 2018), albeit only in certain sectors such as eCommerce, aggregators, fintech, edutech, and healthtech. According to the start-up founders interviewed, there are many incubation centers, accelerators, and coworking spaces across the country, encouraging student startups and entrepreneurs with startup ideas. Universities and government institutions support such startups with technology, mentoring, funding, and buyer-seller meeting facilitation. Over the last five to seven years, there has also been an influx of venture capital and angel investment, including from global investors such as Alibaba, Softbank, Sequoia, and Foxconn, backing new startups. However, when it comes to scaling up from the startup stage to the SME level, there are several bottlenecks. The average size of first round startup-funding is about $\$ 250,000$, compared to $\$ 1$ million in the US. This amount is barely sufficient to meet all expenses. Therefore, due to the lack of adequate opportunities to scale up and realize economies of scale, many of these startups fail. For example, according to Kathak Mehta, a co-founder of Gentlewasher, the initial rounds of angel funding that her venture received came in spurts, only sufficient to take care of the crisis at hand. In retrospect, she thinks, if the initial rounds of funding had been sizeable, they would have been able to produce on larger scale, reduce the per unit cost, and thereby the price of the product. Eventually, they had to discontinue their venture because they did not have sufficient revenues to justify the next round of funding.

\subsection{Patents}

The introduction of stronger IPR laws in India has given rise to an increase in the number of patent applications in the country. It has also led to an increasing trend of MNCs entering India through various routes such as FDI, contract research and manufacturing, outsourced manufacturing, joint ventures, setting up of greenfield ventures, etc. There is also an increase in patents filed in India by foreign R\&D centers. The total number of patents granted during 2017-18 was 13,045 out of which only $1,937(15 \%)$ were granted to Indian applicants. Number of patents in force as of 2018 was 502,864 , out of which only 8,830 (16\%) patents belonged to Indians, and the major part of which belonged to large companies and government organizations (Office of the Controller General of Patents, 2017-18).

Large and innovative companies have benefitted from the new IPR laws. However, SMEs, especially in the pharmaceutical industry are facing difficulties. According to the respondents, lack of awareness, absence of tangible returns on IP, and high legal costs are major disincentives in the IPR process.

Out of the total granted patents in India, the top four categories were chemicals $(25.44 \%)$, mechanical (19.27\%), computer and electronics (10.28\%), and communications $(10.31 \%)$, 
totaling $65.30 \%$ of the patents granted in 2017-18 (Office of the Controller General of Patents, 2017-18).

\subsection{Types and sources of innovation}

Innovations through structured $R \& D$, technology licensing, or employing skilled manpower such as engineers and scientists is more prevalent in larger companies (CSIR-NISTADS, 2014). Around $35 \%$ of the large companies introduce breakthrough technologies through inhouse research (Shah et al., 2014). For large companies, $70 \%$ of the respondents confirmed their organizations had an in-house R\&D facility. However, most of them said R\&D as an activity was only moderately significant in their enterprises, and only $38 \%$ of the large company respondents said that their organizations held patents. Most of the innovations were imitations of products and services from the Western countries, or driven by customer requirements, or compliance to international standards such as ISO or European or American standards.

Amongst the larger companies, there is excitement about smart cities, digitization, and 3D printing technology, as per the primary data. Digitization has helped large organizations measure ROI on innovations and acquire further funding (Edelman Intelligence, 2018). Regulations around privacy and data are, however, preventing businesses from adopting more radical/transformative innovations (Edelman Intelligence, 2018).

On the other hand, SMEs are minimizing risks (CSIR-NISTADS, 2014; Voeten, Saiyed, \& Dutta, 2017). According to primary data, SMEs grapple with survival and operational issues, leaving little space for innovation. Only 35\% of the 9,001 largely MSME companies surveyed by the Indian National Innovation Survey were innovative and most of these innovations are "new to the company" rather than "new to the world" (CSIR-NISTADS, 2014). These new-tocompany innovations were either acquisitions of new machines or were of non-R\&D type, such as marketing, organizational, or incremental innovations (CSIR-NISTADS, 2014; Voeten et al., 2017). Informal exchange of knowledge through networks of domestic friends and occasionally from the Indian diaspora are common (Voeten et al., 2017). According to the interviews and the survey, most of these innovations are driven by customer requirements, or are mere imitations of existing products and services. Startups, in contrast, are more patent and R\&D oriented, striving to bring if not new-to-the-world innovations, then at least innovations that are new to India.

Hence, the hypothesis that large Indian companies are more innovative as compared to small companies in response to the voids and opportunities in the regulatory pillar of the institutional context is verified, albeit innovations in India are also fueled by startups.

\subsection{Public and private R\&D}

While the total $\mathrm{R} \& \mathrm{D}$ expenditure is inadequate, public investments have been constrained by the demands from other public services and private investment is not as forthcoming, as this involves long gestation periods and uncertain returns (Department of Industrial Policy and Promotion, 2017). The increase in business/private R\&D is not substantial. In fact, India's GII ranking in the "R\&D performed by Business" category has gone down from 42 in 2013 to 49 in 2019. According to a study by Forbes (2017), there are only twenty-six Indian companies in the list of the top 2,500 global R\&D spenders, with no firms in five of the top ten R\&D sectors (Government of India Ministry of Finance Department of Economic Affairs Economic Division, 2018). As mentioned in the previous section, the respondents confirmed that R\&D as an activity was considered only moderately significant in large firms. Many of the SME firms did not have a dedicated R\&D department, according to the survey and interviews. 
Besides, R\&D is concentrated in just three sectors: pharmaceuticals, automobiles, and software. In fact, most of the R\&D focuses on the servicification of R\&D linked with the growth of the Information and Communication Technologies (ICT) sector (Joseph, 2019). The same trend continues in FDI in R\&D. ICT; natural sciences and engineering; pharmaceuticals and clinical research are the most prominent sectors that attract the highest FDI in R\&D (Joseph et al., 2019).

\subsection{Collaborative R\&D}

Almost all interviewees agreed that education and R\&D systems work in silos and often do not align with industry needs. In-house research in the industry is straitjacketed and its collaborative efforts with education and government institutions are limited. Wherever there was collaboration, it was limited to use of testing facilities or use of labs. The respondents cited three reasons for this. First, the academia does not have a commercial mindset. Secondly, the technology transfer process is not streamlined; information regarding technologies available for patenting is not readily accessible on the institutions' websites. Recently, public R\&D institutions have been under pressure to be self-sustainable. Therefore, the process of making information regarding patents and technologies available on their respective websites has been underway. Thirdly, in cases where there is collaboration, universities and public R\&D institutions are inclined towards collaborating with larger companies rather than SMEs. SME collaboration is customer driven and is therefore collaborative with clients. Many startups, on the other hand, are housed in universities, incubation centers, and scientific institutions. Hence, they get technological and R\&D support from such institutions.

Therefore, the hypothesis that public $R \& D$ financing stimulates private $R \& D$ financing in India is refuted.

The hypothesis that positive effect of public $R \& D$ financing on private $R \& D$ financing in India differs based on company size, age, and industry sector, is verified. Larger companies and startups witness more collaboration with academia and public R\&D institutions than SMEs. Many of the collaborations involve product testing and are sector-specific. SMEs innovate by means of collaboration with their clients.

\subsection{FDI}

Indian FDI policy has largely aimed at attracting investment without harnessing the benefits of retaining it and taking utmost advantage of the access to technology involved. The FDI policy requires a review to ensure that it facilitates greater technology transfer, leverages strategic linkages and innovation (Department of Industrial Policy and Promotion, 2017).

Multinationals, government, and public authorities are perceived as drivers of innovation among Indian business executives (Edelman Intelligence, 2018). However, despite a consistent increase in FDI in R\&D (\$1047.1 M in 2005 to $\$ 14,063.5$ B in 2015) (Joseph et al., 2019), and leadership in R\&D of "Design, Development and Testing" in terms of the number of companies investing, the number of projects created, and the jobs made possible between 2003 to 2018 Joseph (2019), the investment so far has focused more on meeting market demands of the parent companies of the MNCs located abroad than on the local Indian market. Spillover effects to local companies and R\&D with the intent of augmenting knowledge in the local economy are limited. The linkages with domestic companies are limited to the IT sector and only to a certain extent. In other sectors, these linkages are missing (Basant and Mani, 2012 in Shah et al., 2014; Joseph et al., 2019). In fact, some of the respondents mentioned that MNCs that manufacture and sell in India produce products that are obsolete in the Western markets but 
are new in the Indian market. The Indian companies that are interested in collaborating with MNCs find them less cost competitive.

FDI inflows are again focused in a handful of sectors such as the service sector (which includes the financial sector, outsourcing, $R \& D$, technical analysis and testing, etc.), IT, automobile, drugs and pharmaceuticals, and chemicals (Fact Sheet on FDI, Department of Promotion of Industry and Internal Trade). India has been the preferred recipient of outsourcing contracts which is reflected in the consistently high level of FDI inflow in the service sector.

Hence, the hypothesis that FDI inflows foster innovation in Indian private companies is refuted.

\subsection{Mindset}

According to the respondents, culturally, Indians are not inclined towards early adoption of new and innovative products. They prefer tried and tested products and solutions. They also felt that in larger firms, bureaucracy, hierarchy, paternalistic culture, and lack of proclivity to delegate result in lack of freedom to innovate. Amongst SMEs, survival is the focus rather than growth or innovation. The newer generation, however, is more optimistic, innovation oriented, and open to new entrepreneurial options. Most of the respondents from startups and the younger generation emphatically stated that regarding innovation, Indian culture, mindset, and government policies have seen a massive improvement over the last five to seven years.

Consequently, the hypothesis that newer startups are more innovative as compared to older firms in India because the traditional Indian cultural context did not support corporate innovation, while the evolving cultural context does, is verified.

\subsection{Quality and quantity of talent and strategies for skill training}

Based on the primary survey and interviews, it was found that there is a lot of talent available, however, it is not readily employable. Therefore, lack of talent/inadequate skills is a key challenge for all Indian companies irrespective of size, not to mention the impact of such inadequacy on their innovation capability (Edelman Intelligence, 2018). One of the main reasons for this, according to most respondents, was that the Indian school curriculum does not prepare students for innovation and dissuades them from thinking outside the box.

To eliminate the skills gap, larger companies send their employees abroad for training, or by having them learn from collaborators (CSIR-NISTADS, 2014). In some companies, according to the respondents, there is a rigorous two-year induction program to eliminate the said gap.

In a typical Indian MSME, the average share of scientists and engineers is a meagre $7 \%$ (CSIR-NISTADS, 2014). The primary data revealed that SMEs acquire skills either through "learning by doing" (Whitley, 2000) or in-house training. Training in institutions abroad or learning from collaborators are rare initiatives for SMEs (CSIR-NISTADS, 2014).

As a result, the hypothesis that the lack of adequate skills is a void in the normative institutional context for innovation in Indian companies, large and small, despite the massive demographic dividend, is verified.

\section{Discussion and Key Insights}

Emerging economies like India that are constantly striving to transition to the next level of development, present a mix of opportunities and challenging bottlenecks. The study at hand has answered the questions raised in the first section. The regulatory pillar of institutional environment shows many initiatives and reforms that have provided the impetus for birth of successful startups and inflow of FDI amongst other positive outcomes for innovation. However, there are concerns relating to implementation of the reforms, such as bureaucratic 
delays, major infrastructure bottlenecks, and weak governance that impede the process of innovation. An examination of the normative pillar reveals that culturally, India is less open to innovation; nevertheless, the new wave of entrepreneurship has been changing this course. The cognitive pillar shows promise in terms of an enormous demographic dividend with the highest percentage of working age population in the world. A thriving diaspora that contributes capital, knowledge, and innovation is another massive asset. However, a vast skill gap owing to an insufficient education system is a major concern for all types of Indian firms-large and small.

The institutional context presents more barriers for SMEs than for large companies and startups. As a result, startups and large companies are more innovative than SMEs. Most of Indian innovations are imitative, client driven, or are driven by the necessity of compliance to international quality norms. MNCs, government institutions, and to some extent large Indian companies, are the drivers of innovation in India. There are limited innovation spillovers from MNCS. Most of the innovations are limited to a handful of sectors. Larger companies, although optimistic about the digital transformation and innovation landscape, still face obstacles in accessing data.

Incubation centers, accelerators, coworking spaces, universities, and government institutions support startup innovations. Small-sized venture capital and angel investor funds are also available for these enterprises. Larger companies have in-house R\&D centers and collaborative arrangements with public $\mathrm{R} \& \mathrm{D}$ systems to drive their innovations. They have economies of scale and the scope to build internal systems to develop high-value innovations. Since SMEs do not have access to such resources, they use informal networks and resources as substitutes. All Indian firms address gaps in skill sets through training.

SMEs are focused on new-to-company, new equipment related, and customer-driven innovations. Most of the patents granted belong to large firms, MNCs, and government institutions. Collaborative research with academia/public research institutions is scarce in India.

Overall, the startup ecosystem for innovations has been strengthened over the last five to seven years. If the ecosystem for innovation in SMEs is also bolstered, Indian private industry will continue the innovation trajectory set by the startups. Support in the form of access to capital, skill development, stronger regulatory support, and improvement in educational system starting at school level, are some of the measures government should implement for the SMEs. Indian firms on their part should create a culture that fosters freedom to innovate.

\section{Conclusions}

The study concludes that in the rapidly transitioning institutional context of an emerging economy like India, large firms are more innovative because of their resilience and internal systems and capabilities that can overcome voids and exploit opportunities. Concerning startups and SMEs, the fast-paced transitions create unequal opportunities to companies of different sizes and ages. In the case of India, as mentioned earlier, the opportunities favor startups. Hence, the author posits that in emerging economies, the changes in institutional context provide unequal opportunities and problems for innovation for various groups of companies differentiated by characteristics such as size and age. Each group characterized by its size and age has a distinct coping strategy to overcome the barriers and exploit the opportunities. This study makes an important contribution to the existing literature since such a comprehensive investigation of the impact of every pillar of institutional context on the innovation trajectory across various company sizes and ages in an emerging economy is unique. Since it is a qualitative study, generalization cannot be drawn and applied to other emerging economies. However, a comparative study of similar economies using the above 
framework is required to validate, modify, or invalidate the assessments and provide a generalized theory. Further, a longitudinal, quantitative, and rigorous analysis of data using different methodologies can provide more interesting insights into this growing field of study.

\section{References}

Barros, H. (2015). Exploring the use of patents in a weak institutional environment: The effects of innovation partnerships, firm ownership, and new management practices. Technovation, 45-46, 63-77.

Basant, R. (2006, May). Bangalore cluster: Evolution growth and challenges. Working Paper Series 2005-06.

Berry, H., Guillén, M. F., \& Zhou, N. (2010). An institutional approach to cross-national distance. Journal of International Business Studies, 41(9), 1460-1480.

Casper, S. (2009). Can new technology firms succeed in coordinated market economies? A response to Herrmann and Lange. Socio-Economic Review, 7(2).

Chang, S. J., Chung, C. N., \& Mahmood, I. P. (2006). When and how does business group affiliation promote firm innovation? A tale of two. Organization Studies, 17(5), 637-656.

Chari, M., \& David, P. (2012). Sustaining superior performance in an emerging economy: An empirical test in the Indian context. Strategic Management Journal, 33(2), 217-229.

Chowdhury, F., Siri, T., \& David, A. (2015). Varieties of entrepreneurship: Institutional drivers across entrepreneurial activity and country. European Journal of Law and Economics, 40(1), 121-148.

Cuili, Q., Qing, C., \& Takeuchi, R. (2013). Top management team functional diverstiy and organizational innovation in China; The moderating effects of environment. Strategic Management Journal, 110-120.

Department of Industrial Policy and Promotion, M. o. (2017). Industrial Policy 2017 - A Discussion Paper. Retrieved from https://dipp.gov.in: https://dipp.gov.in/sites/default/files/Industrial_policy_2017_DP.pdf

Dominique, G., \& Pottelsberghe, B. v. (2000). The impact of public R\&D expenditure on business R\&D. OECD Science, Technology and Industry Working Papers.

Edelman Intelligence. (2018). GE Global Innovation Barometer 2018 - India Report. Edelman Intelligence.

Estrin, S., M. K., \& Pelletier, A. (2018). Emerging economy MNEs: How does home country munificence matter? Journal of World Business, 53(4), 514-528.

Fan, P. (2018). Catching up in economic transition: Innovation in the Perople's Republic of China and India. ADBI Working Paper Series, No. 809.

Fulvio, C. (2015). Institutional voids or organizational resilience? Business groups, innovation, and market development in Latin America. World Development, (70), 43-58.

IBEF (2019). Science and Technology. Indian Brand Equity Foundation.

IBEF (2019, March). $T$ \& ITeS Industry in India. Retrieved from Indian Brand Equity Foundation (IBEF): https://www.ibef.org/industry/information-technology-india.aspx.

Iris, W., Thomas, S., \& Fischer, M. M. (2013). How do firm characteristics affect behavioural additionalities of public R\&D subsidies? Evidence for the Austrian transport sector. Technovation, (33), 66-77.

Jie, W., Zhenzhong, M., Zhiyang, L., \& Chun Kwok, L. (2019). A contingent view of institutional environment, firm capability, and innovation performance of emerging multinational enterprises. Indsutrial Marketing Management (89), 148-157.

Joseph, R. (2019, August). Global Innovation Index 2019: Key takeaways for India. Retrieved from Observer Research Foundation: https://www.orfonline.org/expert-speak/global-innovation-index-2019-key-takeawaysindia-54919/.

Joseph, R., Dhar, B., \& Singh, A. (2019, June). FDI in R\&DI in India: An analysis of recent trends. Working Paper 209.

Jyrki, A.-Y. (2005). Impact of public R\&D financing on private R\&D; Does financial constraint matter? ENEPRI Working Paper, No. 30.

Khanna, T., \& Palepu, K. (2000). The future of business groups in emerging markets: Long-run evidence from Chile. Academy of Management Journal, 43(3), 268-285.

Kshetri, N. (2011). The Indian environment for entrepreneurship and small business development. Studia Negotia, $56(4), 35-52$.

Lerouge, C., Newton, S., \& Blanton, J. (2005). Exploring the systems analyst skill set: perceptions, preferences, age, and gender. Journal of Computational Information System, 45(3), 12-23.

Mueller, V., Rosenbusch, N., \& Bausch, A. (2013). Success patterns of exploratory and exploitative innovation: a meta-analysis of the influence of institutonal factors. Journal of Management, 39(6), 1606-1636.

Nelson, R. (1988). Institutions supporting technical change in the United States. In G. F. Dosi, Technical Change and Economic Theory. London: Pinter Publishers.

Periyanayagam, A., \& Goli, S. (2012). Provisional results of the 2011 Census of India-slowdown in growth, ascent in literacy, but more missing girls. International Journal of Socioeconomics, 39(10), 785-801. 
Richerson, P. J., Boyd, R., \& Bettinger, R. L. (2009). Cultural innovations and demographic change. Human Biology, 81(2), 211-235.

Ruifa, H., Qin, L., Carl, P., Jikun, H., \& Jin, Y. (2011). Privatization, public R\&D policy, and private R\&D investment in China's agriculture. Journal of Agricultural and Resource Economics, 36(2), 416-432.

Saul, L. (2002). Do R\&D subsidies stimulate or displace private R\&D? Evidence from Israel. The Journal of Industrial Economics, 50(4), 369-390.

Simon-Moya, V., Revuelto-Taboada, L., \& Guerrero, R. (2014). Institutional and economic drivrs of entrepreneurship: An international perspective. Journal of Business Research, 67, 715-721.

Stankevice, I., \& Jucevicius, G. (2013). Institutional vs. sectoral dimension of innovation strategies of firms. Technological and Economic Development of Economy, 19.

United Nations; Department of economic and social affairs; Population divisiton. (2019). World Population Prospects. United Nations.

Voeten, J., Saiyed, A., \& Dutta, D. (2017). Emerging economies, institutional voids, and innovation drive: A study in India. DFID Working Paper, Tilburg University.

Whitley, R. (2000). The institutional structuring of innovation strategies: business systems, firm types and patterns of technical change in different market economies. Organization Studies, 21(5), 855-866.

Xulia, G., \& Consuelo, P. (2008). Do public subsidies stimulate private R\&D spending? Research Policy, 37(3), 371-389.

Yan, Z., Zhu, J., Fan, D., \& Kalfadellis, P. (2018). An institutional work view toward the internationalization of emerging market firms. Journal of World Business, 53(5), 682-694.

Zuleta, V. A. (2007). Two paths to prosperity when property rights enforcement is weak. Journal of Globalization, Competitiveness, and Governability, 1(1).

Cornell University; INSEAD; WIPO. (2019). Global Innovation Index 2019: Creating Healthy Lives - The future of Medical Innovation. Ithaca; Fountainebleau; Geneva: WIPO and CII.

CSIR-NISTADS (2014). Understandting innovation - Indian National Innovation Survey with special focus on MSMEs. New Delhi: NSTIMS, Department of Science and Technology, GOI.

Government of India Ministry of Finance Department of Economic Affairs Economic Division. (2018). Economic Survey of India 2017-18. New Delhi: Government of India.

Government of India Ministry of Commerce and Industry - Department of Industrial Policy and Promotion. (2018). States Startup Ranking. New Delhi: Government of India.

Krishnan, R. (2010). From Jugaad to Systematic Innovation - The challenge for India. Bangalore: The Utprerka Foundation.

Lewin, A. Y., \& Volberda, H. W. (2005). The future of organization studies: Beyond the selection-adaptation debate, in . In H. Tsoukas, \& C. Knudsen, Oxford Handbook of Organization Theory: Meta-Theoretical Perspectives. 1st ed. (p. 568). Oxford University Press.

North, D. (1990). Institutions, institutional change, and economic performance. Cambridge, UK: Cambridge University Press.

Scott, W. (1995). Institutions and organizations. Foundations for organizational science. London: A Sage Publication Series.

Shah, G. M. (2014). Innovation, entrepreneurship, and the economy in the US, China, and India: Historical perspectives and future trends. Academic Press: Elsevier Publication.

WIPO, \& INSEAD. (2013). Global Innovation Index 2013: The local dynamics of innovation. WIPO-INSEAd.

ihttps://evoma.com/business-centre/sme-sector-in-india-statistics-trends-reports/

$\mathrm{i}_{\mathrm{i}}$ "Research and Development Statistics at a glance." http://www.nstmis-dst.org/ accessed on Jan 16, 2020

iii https://www.weforum.org/agenda/2018/10/here-s-what-young-indians-really-want-from-life/ accessed on Apr $11,2020$.

${ }^{\text {iv } h t t p s: / / w w w . s t a r t u p i n d i a . g o v . i n / c o n t e n t / s i h / e n / s t a r t u p-s c h e m e / I n t e r n a t i o n a l / i n d i a n-s t a r t u p-e c o s y s t e m . h t m l ~}$

vhttps://www.wipo.int/edocs/pubdocs/en/wipo_natstudy_sme_india.pdf_accessed on Apr 11, 2020.

vi Thehasin Nazia \& Rajarshi Choudhuri: 2019. "The Problem of IPR Infringement in India's Burgeoning Startup Ecosystem." IPwatchdog https://www.ipwatchdog.com/2019/11/16/problem-ipr-infringement-indiasburgeoning-startup-ecosystem/id=116019/ accessed on Jan 16, 2020

vii“"Intellectual Property Rights in India." Intellectual Property Office, UK. https://assets.publishing.service.gov.uk/government/uploads/system/uploads/attachment_data/file/627956/IP -Rights-in-India.pdf accessed on 16th January, 2020

viii Parikh, Benjamin: 2019. "Has the 'Make in India' campaign run out of steam?" Financial Times. https://www.ft.com/content/3fbe1c46-0c7f-11ea-8fb7-8fcec0c3b0f9 accessed on Jan 21,2020 
Ekonomicko-manazerske spektrum

2020, Volume 14, Issue 2, pp. 36-51

\section{Appendix-1}

\begin{tabular}{ll}
\hline Name of the respondent & Company name \\
\hline Abhishek Chandra & KHS Machinery Pvt Ltd \\
Manthan Shah & La-Gajjar Machineries Pvt Ltd \\
Anand Parikh & Shira Med Tech \\
Shubendhu Kumar Dash & Consytel Life Sciences Pvt Ltd \\
Prashant Mittal & Corrtech Energy Ltd \\
Kathak Mehta & Gentlewasher \\
Balaji Vasudevan & Wanbury Ltd \\
\hline
\end{tabular}

